\title{
Incidental thyroid uptake on PET scanning: epidemiology, clinical significance, and management challenge
}

\author{
Sarah Corn ${ }^{1,2}$, Elliot Mitmaker ${ }^{1}$, Roger Tabah ${ }^{1}$, Anthony Ciarallo ${ }^{3}$, Jacques How ${ }^{4}$ \\ 'Divisions of General Surgery and Surgical Oncology, Department of Surgery and Gerald Bronfman Department of Oncology, \\ McGill University Health Center, Montreal, Quebec H4A 3J1, Canada. \\ ${ }^{2}$ Department of Surgery, University of Kansas School of Medicine, Wichita, KS 67214, USA. \\ ${ }^{3}$ Division of Nuclear Medicine, Department of Diagnostic Radiology, McGill University Health Center, Montreal, Quebec H4A \\ 3J1, Canada. \\ ${ }^{4}$ Division of Endocrinology, McGill University Health Center, Montreal, Quebec H3Y 1A4, Canada.
}

Correspondence to: Dr. Jacques How, Division of Endocrinology, McGill University Health Center, 1650 Cedar Avenue, Montreal, Quebec, H3Y1A4, Canada. E-mail: jacques.how@mcgill.ca

How to cite this article: Corn S, Mitmaker E, Tabah R, Ciarallo A, How J. Incidental thyroid uptake on PET scanning: epidemiology, clinical significance, and management challenge. J Cancer Metastasis Treat 2021;7:41.

https://dx.doi.org/10.20517/2394-4722.2021.63

Received: 13 Mar 2021 First Decision: 6 May 2021 Revised: 13 May 2021 Accepted: 24 May 2021 First online: 26 May 2021

Academic Editor: Jerome M. Hershman Copy Editor: Yue-Yue Zhang Production Editor: Yue-Yue Zhang

\begin{abstract}
Incidental lesions of the thyroid are increasingly discovered as the prevalence of medical imaging escalates. The likelihood of malignancy must be assessed for each of these incidentalomas. The utility of the metabolic data derived from the identification of these lesions on PET/CT imaging is unclear. The overall rate of detection of thyroid incidentalomas on PET/CT is estimated at 1.5\%-4.2\%. However, this rate varies by the pattern of uptake. Several studies have evaluated predictive measures such as maximal standardized uptake value $\left(S_{\text {SUax }}\right)$ and radiomics. However, no definitive conclusion has been reached. Given that the majority of PET/CT scans are performed in the context of malignancy, we recommend first assessing the general condition and life expectancy of patients when PET-detected thyroid incidentalomas are unveiled. We also recommend considering observation versus diagnostic workup with further imaging and/or fine-needle aspiration and cytology.
\end{abstract}

Keywords: PEToma, PET-detected thyroid incidentaloma, PET-associated incidental neoplasm 


\section{INTRODUCTION}

The relatively rapid development and diffusion of medical imaging technology have afforded tremendous benefits in the non-invasive evaluation of many benign and malignant lesions. Most forms of diagnostic imaging showed a growth rate of 2- to 6-fold between 2000 and 2016 in both the United States and Ontario, Canada $^{[1]}$, a trend expected worldwide. Imaging studies may be performed for a multitude of reasons, such as screening, staging, or surveillance of cancerous and noncancerous diagnoses. While studies may be undertaken for a specific and targeted purpose, the possibility of unveiling incidental lesions cannot be ignored. The likelihood of revealing an incidental finding varies substantially ( $<5 \%$ to $22 \%$ ) depending on the chosen imaging modality ${ }^{[2]}$.

The primary concern of an incidentally discovered lesion, commonly termed an incidentaloma, relates to the associated risk of malignancy. While all imaging modalities may unveil incidentalomas, the metabolic data afforded by functional imaging such as ${ }^{18} \mathrm{~F}$-FDG PET/CT may provide further information to decipher the clinical relevance of such lesions. ${ }^{18} \mathrm{~F}-\mathrm{FDG}$ is a glucose analog that shows uptake levels corresponding to glycolysis rates and glucose consumption. It is frequently elevated in cancerous tissues due to inefficient aerobic glycolysis (termed the Warburg effect) ${ }^{[3]}$. Physiologic FDG uptake is reported in brown fat, skeletal muscle, lymphoid tissue, and the thymus ${ }^{[4]}$. Multiple benign etiologies, primarily inflammatory or infectious in origin, may also exhibit uptake due to increased rates of glucose metabolism ${ }^{[5,6]}$. Studies reveal a $1.2 \%$ $1.7 \%$ overall detection rate of unexpected malignancies or premalignant lesions in patients undergoing PET/CT evaluation ${ }^{[7,8]}$.

Furthermore, second primary malignancies were described in 4.1\%-8.5\% of PET/CT scans completed for staging or surveillance purposes ${ }^{[8-10]}$. Interestingly, some studies describe a higher likelihood of incidentalomas in patients undergoing PET/CT for screening purposes (3.0\%-3.1\%) compared to the evaluation of known or suspected cancer $(1.9 \%-2.3 \%)^{[11,12]}$. Given the estimated 2 million PET/CT scans performed annually in the United States, these small fractions add up to a significant number of lesions that must be addressed.

Incidentally discovered lesions in the thyroid are uncovered in $21 \%-34 \%$ of ultrasound examinations ${ }^{[13-15]}$ and $16 \%$ of CT or MRI scans ${ }^{[16,17]}$. Among these lesions, the risk of malignancy is reported to range from $1.5 \%-11 \%{ }^{[18,19]}$. On PET scans, the thyroid gland exhibits very low physiologic FDG avidity. However this is typically less than the background blood pool and is usually not clearly visualized on the whole-body fusion PET/CT images ${ }^{[5]}$, which aligns with the observation that the primary energy substrate for the thyroid is free fatty acids ${ }^{[20,21]}$. In contrast, oncocytic/Hürthle cell lesions (both benign and malignant) are known to exhibit FDG-avidity due to an intrinsic mitochondrial defect that results in inefficient glycolytic metabolism ${ }^{[22,23]}$. In addition, thyroid malignancies, such as papillary, follicular, and anaplastic carcinomas and thyroid lymphoma, may also be expected to exhibit increased FDG uptake due to increased glucose metabolism.

Incidental FDG-avid uptake in the thyroid gland exists in two predominant patterns - focal and diffuse. The overall detection rate of thyroid incidentalomas on PET/CT, irrespective of uptake patterns, is estimated at $1.5 \%-4.2 \%{ }^{[8,18,24-36]}$. Most reports attribute a risk of malignancy of $5.1 \%-22.0 \%$ of these PET-detected thyroid incidentalomas ${ }^{[8,28,31,33,35]}$, notably higher than those detected by ultrasound or $\mathrm{CT}^{[37]}$. Similar rates of thyroid incidentaloma detection and associated malignancy are noted amongst those undergoing surveillance of a known cancer and the general population undergoing screening with PET/CT ${ }^{[38]}$.

In this review, we will first discuss the abnormal patterns of FDG uptake in the thyroid gland and the associated risk of cancer, and the types of cancers diagnosed. Next, we will describe specific imaging features 
and their ability to discriminate benign from malignant disease, together with related mutational analysis findings. Finally, we will provide recommendations for the evaluation and management of thyroid incidentalomas.

\section{PATTERNS OF FDG UPTAKE IN THE THYROID GLAND}

Lesions incidentally detected on PET/CT imaging may be referred to as PET-associated incidental neoplasms ${ }^{[39]}$. Within the thyroid, FDG uptake has been described in focal and diffuse patterns or combinations thereof. In general, lesions are designated as focal when the focus of uptake comprises less than one lobe of the thyroid, although such lesions may be multifocal and thus occur bilaterally. The term diffuse is applied when homogenous uptake is identified. Diffuse-plus-focal uptake has been described as focal lesions overlying a background of diffuse uptake. Table 1 describes the incidence of thyroid incidentalomas noted in selected references along with the absolute numbers of malignancies diagnosed. Unfortunately, it is impossible to determine the true rate of malignancy in this population as a significant proportion of patients do not undergo further investigation due to their underlying disease status.

\section{Focal FDG uptake (see example, Figure 1)}

Focal thyroid uptake is defined as FDG avidity occurring in less than one lobe of the thyroid gland ${ }^{[24]}$, for which we suggested the term PEToma ${ }^{[18]}$. The prevalence of such lesions is reported in approximately $0.5 \%$ $2.5 \%$ of PET/CT imaging studies ${ }^{[18,24-27,29,30,32,33,35,36,46]}$. Most of these studies describe a slightly higher rate of detection of focal $v s$. diffuse patterns of uptake. The malignancy risk amongst the former lesions seems to be greater, with rates ranging from $8.6 \%-50 \%^{[18,24-27,29,33,35,46]}$. In Asian countries, the rate of focal uptake has been reported to be double that of American studies, yet the rate of cancer is unchanged ${ }^{[31]}$.

A retrospective study of 4726 patients (6457 FDG PET/CT scans) at our institution ${ }^{[18]}$ revealed a $3.4 \%$ rate of thyroid incidentalomas (160 of 6457 PET/CT scans). Focal uptake was noted in 2.2\% (103 patients), and uptake was diffuse in $1.2 \%$ (57 patients). Fifty patients with focal uptake underwent further workup with imaging and/or fine-needle aspiration and cytology (FNAC), and thyroidectomy was completed in 10 patients. Nine of the ten surgical patients were ultimately diagnosed with papillary thyroid carcinoma on final histopathology: two micropapillary carcinomas, two extrathyroidal extensions, four multifocal involvement, and one had $>50 \%$ poorly differentiated papillary thyroid carcinoma. Thirty percent of the PETomas that received a tissue diagnosis (FNAC and/or histology) were cancerous, which relates to $8.7 \%$ of all focal thyroid lesions.

Amongst countries with known iodine deficiency, the frequency of focal thyroid uptake is unexpectedly reported to be at rates lower than the average, with incidences of $1.0 \%-1.8 \%{ }^{[3,48-50]}$. The risk of malignancy seems similar, with cancers reported in $23 \%-59 \%$ of patients ${ }^{[51]}$, and iodine supplementation programs have done little to change these rates ${ }^{[26]}$.

\section{Diffuse FDG uptake (see example, Figure 2)}

Diffuse FDG uptake is reported in most studies at slightly lower rates than focal uptake. However, it was studied in Japan much earlier, more than two decades ago. Yasuda et al. ${ }^{[52]}$ investigated 1102 healthy subjects using the ${ }^{18}$ F-FDG PET scan, and they detected diffuse FDG thyroidal uptake in 36 (3.26\%), only one of whom was found to have hypothyroidism. Furthermore, antithyroid antibodies were positive in 27 subjects, which led these authors to conclude that diffuse thyroidal FDG uptake may be an indicator of chronic thyroiditis. 
Table 1. Incidence and malignancy in PET-detected thyroid incidentalomas

\begin{tabular}{|c|c|c|c|c|c|c|c|c|c|}
\hline \multirow[b]{2}{*}{ Authors } & \multirow[b]{2}{*}{ Country } & \multirow[b]{2}{*}{$\begin{array}{l}\text { \#PET/CT } \\
\text { scans }\end{array}$} & \multicolumn{4}{|c|}{ Incidence } & \multicolumn{3}{|c|}{ Malignancy } \\
\hline & & & Cumulative & Focal & Diffuse & $\begin{array}{l}\text { Diffuse + } \\
\text { focal }\end{array}$ & Focal & Diffuse & $\begin{array}{l}\text { Diffuse + } \\
\text { focal }\end{array}$ \\
\hline Ceriani et al. ${ }^{[25]}$ & Switzerland & 12,652 & $333(2.6 \%)$ & $187(1.5 \%)$ & $146(1.2 \%)$ & - & 30 & - & - \\
\hline Beck et al. ${ }^{[40]}$ & USA & 35,124 & - & $\begin{array}{l}227 \\
(0.6 \%)\end{array}$ & - & - & 59 & - & - \\
\hline Kim et al. ${ }^{[41]}$ & Korea & $39,098^{\star}$ & - & - & $\begin{array}{l}635 \\
(1.6 \%)\end{array}$ & - & - & - & - \\
\hline Gedberg et al. ${ }^{[26]}$ & Denmark & 2451 & - & $59(2.4 \%)$ & - & - & 10 & - & - \\
\hline Pattison et al. ${ }^{[32]}$ & Australia & 45,680 & - & $\begin{array}{l}500 \\
(1.1 \%)\end{array}$ & - & - & - & - & - \\
\hline Ozderya et al. ${ }^{[42]}$ & Turkey & 6873 & $138(2.0 \%)$ & $\begin{array}{l}135 \\
(2.0 \%)\end{array}$ & $3(0.04 \%)$ & - & 27 & - & - \\
\hline Makis et al. ${ }^{[43]}$ & Canada & 7252 & - & $\begin{array}{l}157 \\
(2.2 \%)\end{array}$ & - & - & 14 & - & - \\
\hline Sencan Eren et al. ${ }^{[35] \dagger}$ & Turkey & 4204 & $178(4.2 \%)$ & $68(1.6 \%)$ & $35(0.8 \%)$ & $13(0.3 \%)$ & 11 & - & 4 \\
\hline Kim et al. ${ }^{[24]}$ & Korea & 18,172 & - & $\begin{array}{l}358 \\
(2.0 \%)\end{array}$ & - & - & 51 & - & - \\
\hline Chun et al. ${ }^{[29]}$ & Korea & 2584 & - & $52(2.0 \%)$ & - & - & 15 & - & - \\
\hline Jamsek et al. ${ }^{[36]}$ & Slovenia & 5911 & $230(3.9 \%)$ & $\begin{array}{l}148 \\
(2.5 \%)\end{array}$ & $82(1.4 \%)$ & - & 10 & - & - \\
\hline Brindle et al. ${ }^{[33]}$ & UK & 7221 & $156(2.2 \%)$ & $81(1.1 \%)$ & $75(1.0 \%)$ & - & 7 & 1 & - \\
\hline Lee et al. ${ }^{[30]}$ & Korea & 2368 & - & $64(2.7 \%)$ & - & - & 11 & - & - \\
\hline Nishimori et al. ${ }^{[18]}$ & Canada & 6457 & $160(2.5 \%)$ & $\begin{array}{l}103 \\
(1.6 \%)\end{array}$ & $57(0.9 \%)$ & - & 9 & 0 & - \\
\hline Kang et al. ${ }^{[44]}$ & Korea & $12,840^{*}$ & $1151(9.0 \%)$ & $\begin{array}{l}612 \\
(4.8 \%)\end{array}$ & $\begin{array}{l}539 \\
(4.2 \%)\end{array}$ & - & 55 & 2 & - \\
\hline Chen et al. ${ }^{[45]}$ & USA & 2594 & 99 (3.8\%) & $53(2.0 \%)$ & $46(1.8 \%)$ & - & 7 & 0 & - \\
\hline Karantanis et al. ${ }^{[34]}$ & USA & 4732 & - & - & $\begin{array}{l}138 \\
(2.9 \%)\end{array}$ & - & - & 0 & - \\
\hline Kurata et al. ${ }^{[46]}$ & Japan & 1626 & - & - & $25(1.5 \%)$ & $4(0.24 \%)$ & - & 1 & 2 \\
\hline Choi et al. ${ }^{[16]}$ & Korea & 1763 & - & $65(3.7 \%)$ & - & $5(0.28 \%)$ & 18 & - & 0 \\
\hline $\begin{array}{l}\text { Nockel et al. }{ }^{[47] \dagger \dagger} \\
\text { DOTATATE }\end{array}$ & USA & 237 & $26(11.0 \%)$ & $14(5.9 \%)$ & $12(5.1 \%)$ & - & 3 & 0 & - \\
\hline
\end{tabular}

\#Number of PET/CT scans. *Study population included PET/CT scans completed for screening/preventative measures. "Prospective study.

In a review of eight studies, the frequency of diffuse FDG uptake ranged from $0.1 \%-4.5 \%$, with a mean of $1.9 \%^{[11,38,44,45,48,53-55]}$. Contemporary studies con similar to Yasuda et al..$^{[52]}$, namely that the diffuse uptake pattern is an indication of benign disease $\mathrm{e}^{[34,37,46]}$, predominantly attributed to inflammatory or autoimmune forms of thyroiditis such as Hashimoto's thyroiditis. Of note, only $10 \%$ of patients with these conditions exhibit diffuse FDG uptake on PET scan ${ }^{[56]}$, and studies report chronic thyroiditis as the etiology of diffuse uptake in $47 \%-100 \%$ of patients ${ }^{[3,45,54]}$. Furthermore, there is no apparent relationship between serum TSH levels and diffuse FDG avidity in patients diagnosed with thyroiditis, and thyroid hormone replacement seems to have no effect on patterns of uptake $e^{[34,5]}$. The afore-mentioned studies were cross-sectional so that any impact of incidentally identified diffuse uptake on subsequent thyroid dysfunction was unclear. Kim et al. ${ }^{[41]}$ did a cross-sectional and longitudinal study on 39,098 subjects undergoing comprehensive health examinations. At baseline, the prevalence of diffuse thyroidal FDG uptake was 1.6\%. During 104,261.4 person-years of follow-up, 102 incident hypothyroid cases and 172 hyperthyroid cases were identified. The multivariable-adjusted HR for incident hypothyroidism and hyperthyroidism (comparing diffuse uptake to no uptake) were 15.72 and 7.38, respectively. Thus, euthyroid patients identified with diffuse thyroid uptake on PET scan should be regarded as being at risk for future development of thyroid 


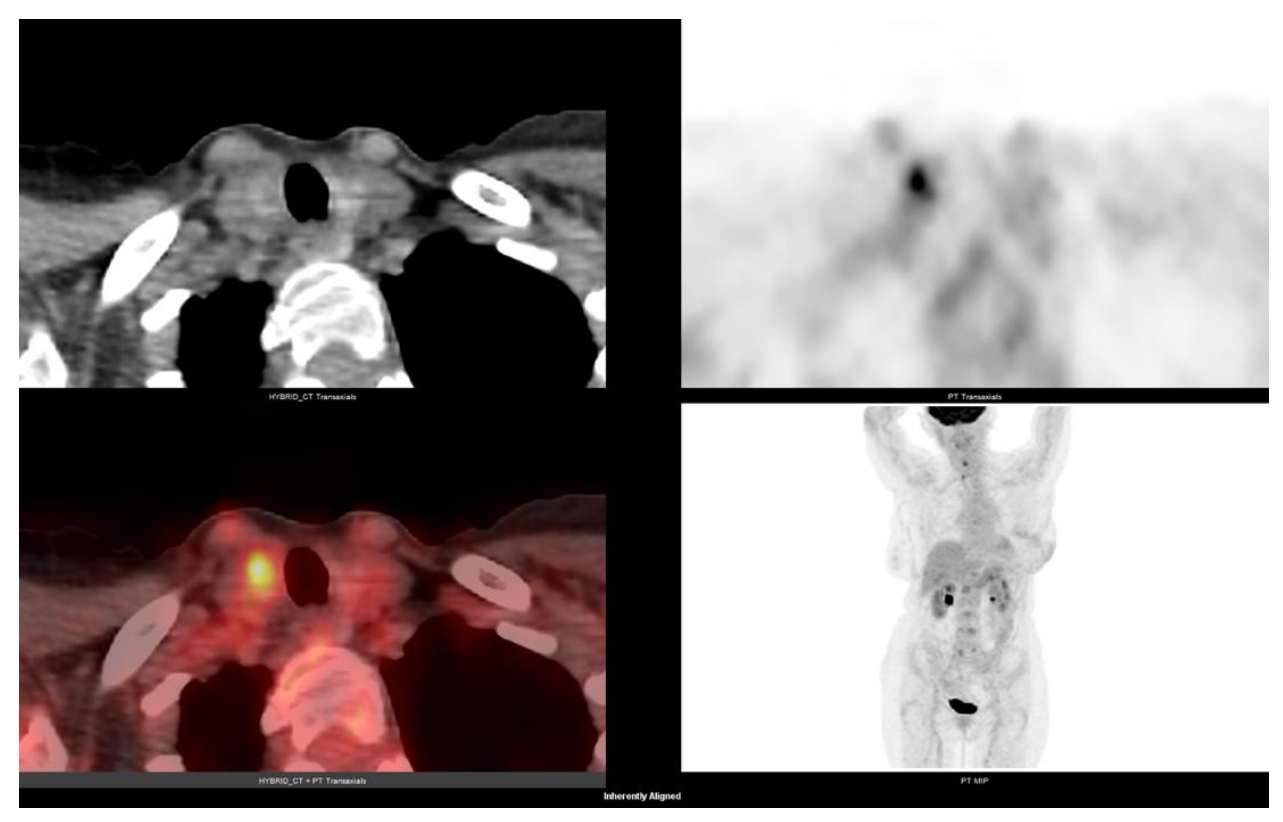

Figure 1. This is a case of focal thyroid FDG uptake in a 79-year-old female who underwent PET scanning for known laryngeal cancer. This revealed a $1.1 \mathrm{~cm}$ thyroid lesion in the right lower thyroid pole, SUV 6.0.

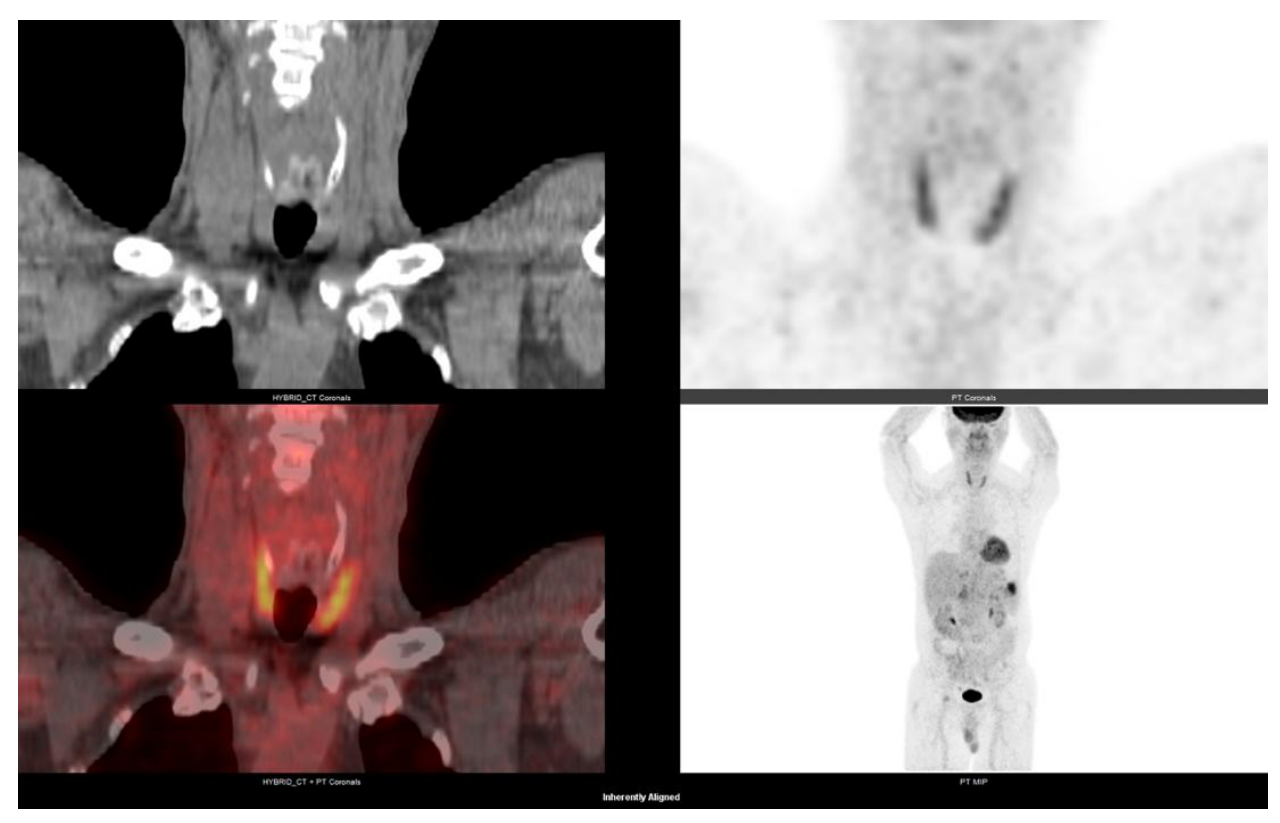

Figure 2. This is a case of mild diffuse FDG uptake throughout the thyroid with SUV 3.7 in a patient undergoing PET scanning for known metastatic sarcoma.

dysfunction and should be followed up. One of the major limitations of this paper is that $93.4 \%$ of the participants were male.

Of note, Kim et al. ${ }^{[58]}$ selected for study 290 women with breast cancer who had undergone PET-CT scans before and after breast surgery and diffuse thyroidal uptake developed in 23 (9.3\%) patients. Radiotherapy in breast cancer was found to be an independent predictive factor for the development of new diffuse thyroidal 
uptake. Similar observations on the impact of radiotherapy on the emergence of the diffuse thyroidal uptake were made by Hassan et al. ${ }^{[27]}$.

The risk of malignancy in patients found to have diffuse thyroidal uptake on PET scan is very low, with a quoted range of $0.6 \%-3.5 \%$ in the literature ${ }^{[5,57]}$. In a recent systematic analysis of 26 published articles encompassing 2255 cases, only one patient of differentiated thyroid cancer without thyroiditis displayed a diffuse thyroidal uptake. While in 4 other cases, differentiated thyroid cancer was present alongside thyroiditis. In addition, primary thyroid lymphoma was diagnosed in 10 cases $^{[5]}$.

\section{Diffuse-plus-focal FDG uptake (see example, Figure 3)}

Diffuse-plus-focal uptake describes the simultaneous occurrence of 1 or more focal FDG-avid thyroid lesions on a background of diffuse uptake, which was first described in 2006 by Choi et al. ${ }^{[16]}$, who identified and reported this FDG thyroidal uptake variant in five patients among their 1763 subjects, yielding a prevalence of $0.28 \%$. None of these 5 patients had malignancy, while three patients were judged to have chronic thyroiditis based on pathology $(n=2)$ and ultrasound imaging $(n=1)$. The preliminary conclusion was that a diffuse-plus-focal ${ }^{18} \mathrm{FDG}$ uptake pattern might have the same clinical significance as a diffuse pattern.

Kurata et al. ${ }^{[46]}$ studied 1626 subjects who underwent PET scanning and unveiled 4 patients exhibiting the diffuse-plus-focal uptake (prevalence $0.24 \%$ ). Two patients were confirmed to have papillary thyroid carcinoma associated with Hashimoto's thyroiditis, while the other two had adenomatous goiter associated with Hashimoto's thyroiditis. More recently, Sencan Eren et al. ${ }^{[35]}$ published the results of their prospective study of 4202 patients, uncovering this diffuse-plus-focal pattern in 13 (prevalence $0.309 \%$ ). Twelve of the latter group had adequate investigations allowing the recognition of malignancy in four (33.3\%).

Thus, we presently have limited published data on this group of patients with simultaneous focal and diffuse uptake. However, it would appear that the diffuse component here is most often attributable to benign entities, especially chronic lymphocytic thyroiditis. The underlying pathology of the focal component would appear to be more heterogeneous, including benign Hashimoto's thyroiditis, adenomatous goiter and thyroid malignancy. It is well-established that the thyroid parenchyma is diffusely heterogenous in Hashimoto's thyroiditis, and formation of focal lymphocytic thyroiditis nodule may occur in some patients ${ }^{[59,60]}$. This schema may have been operative in the five patients of Choi et al.$^{[16]}$. On the other hand, the findings of Kurata et al.$^{[46]}$ and Sencan Eren et al.$^{[35]}$ underscore the increased risk for malignancy in this subset of patients with diffuse-plus-focal uptake. Further data are needed for proper management guidance. But meanwhile, it is our view that patients with the diffuse-plus-focal uptake should be investigated in a manner similar to patients with focal uptake.

\section{Progression of focal to diffuse thyroid uptake}

This entity is extremely rare, having been described in a single case report, but is very challenging in need to differentiate malignant metastatic disease from benign thyroiditis. Thuillier et al. ${ }^{[6]]}$ reported the case of a 49-year-old man presenting with cerebral metastasis of unknown primary, and the ${ }^{18} \mathrm{~F}$-FDG PET/CT scan disclosed an incidental left focal thyroid uptake, while the thyroid ultrasound was considered consistent with thyroiditis. Upon the diagnosis of lung adenocarcinoma, pembrolizumab treatment was initiated. A follow-up PET/CT scan revealed the progression of focal thyroid uptake to an intense diffuse uptake $\left(\mathrm{SUV}_{\max }\right.$ 18.2). A fine-needle aspiration biopsy of the thyroid parenchyma indicated a diffuse involvement from lung adenocarcinoma. 

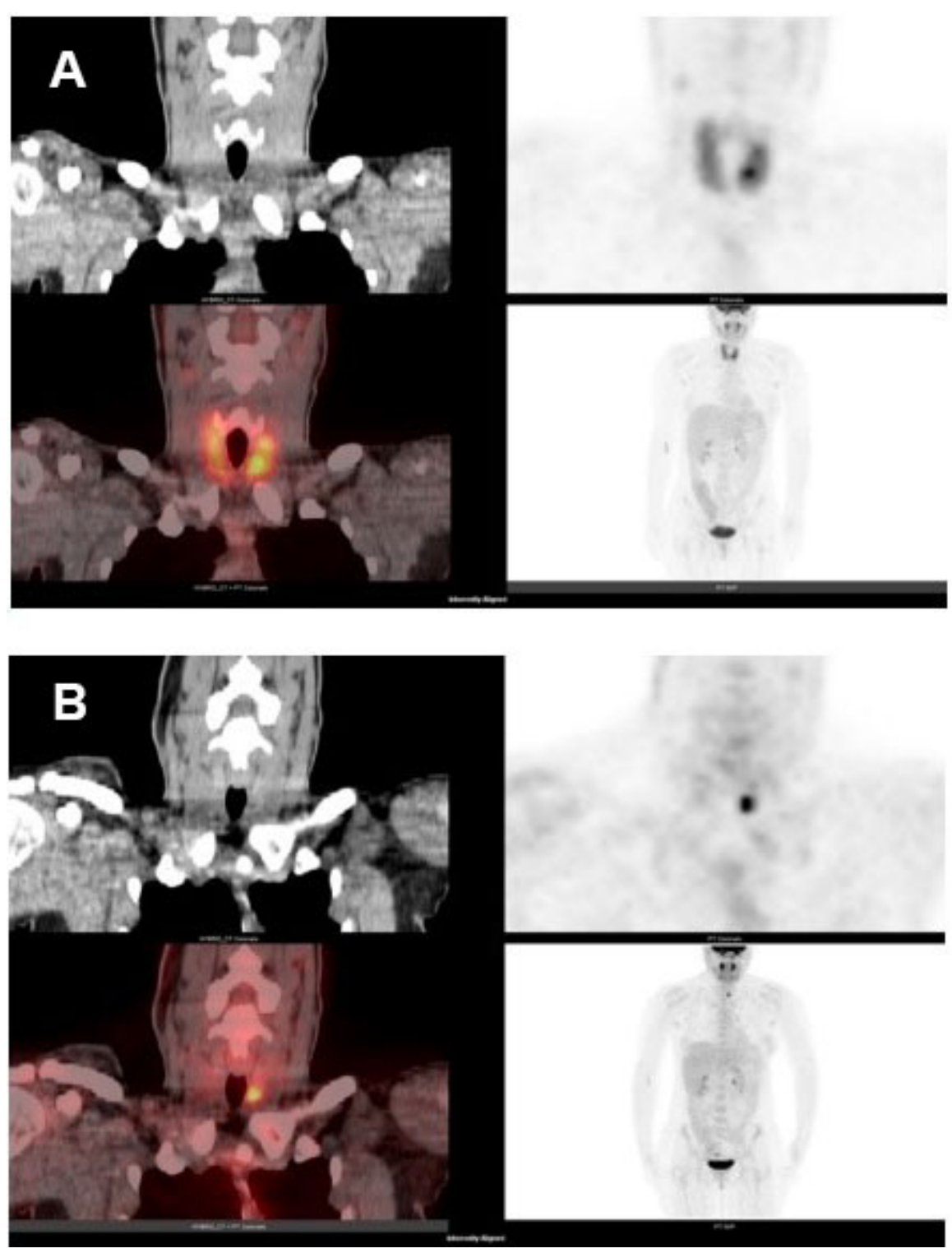

Figure 3. This is a case of diffuse-plus-focal FDG uptake transitioned to focal uptake in a patient with Stage III melanoma. (A) Diffuseplus-focal FDG uptake (diffuse SUV 8.4, focal SUV 12.8) in the thyroid during treatment with interferon therapy resulting in induced primary hypothyroidism treated with I-T4. (B) FDG uptake regressed after treatment of thyroiditis to a focal area of increased uptake in the left thyroid lobe, SUV 9.8. Final pathology after total thyroidectomy showed multifocal papillary thyroid carcinoma.

\section{Self-resolving variant}

In our study of 6457 FDG-PET scans, we identified 103 patients with incidental focal thyroid uptake (PETomas), and unexpectedly 5 patients $(4.9 \%)$ demonstrated self-resolution of the PETomas ${ }^{[18]}$. This phenomenon is probably overlooked, mainly because the published data on PETomas are invariably crosssectional studies.

In a recent, detailed study of 47 patients with thyroid PETomas, Poller et al. ${ }^{[62]}$ could not identify any specific cytological or histopathological cause in 14 (29.8\%) of these lesions. The time frame between the discovery of the PEToma and the final diagnosis was not mentioned. But it is conceivable that some of the patients in this series manifested a natural history evolving towards self-resolution. The reasons underlying 
this process are unknown.

\section{Tumor types and uptake patterns}

Papillary thyroid cancer accounts for nearly $90 \%$ of all cases of thyroid carcinomas ${ }^{[63]}$. Primary thyroid carcinomas would be expected to make up the majority of thyroid incidentalomas, however it is important to recognize that metastases and thyroid lymphomas have also been described. This is significant as it may prompt a change in prognosis and treatment. A meta-analysis identified $1.1 \%$ of PET-detected thyroid incidentalomas to represent metastatic disease and a 19.8\% overall malignancy rate (with $15.4 \%$ representing papillary thyroid carcinoma $)^{[64]}$. Metastases to the thyroid were described with solitary focal, multiple focal, and diffuse patterns of FDG avidity ${ }^{[65]}$. Table 2 includes tumor types diagnosed by either cytopathology or histopathology in studies reporting this information.

\section{IMAGING CHARACTERISTICS}

Although generally uncommon, focal thyroid incidentalomas are reported at higher frequencies than diffuse lesions, and the associated rate of malignancy is greater. Therefore, imaging characteristics, such as the magnitude of FDG uptake, have been postulated to adjust for malignancy risk.

\section{Standardized uptake value}

Standardized uptake values (SUV) are commonly reported to quantify the magnitude of FDG uptake on PET/CT. Several studies have evaluated the ability of $\mathrm{SUV}_{\max }$ to discriminate malignant from benign thyroid incidentalomas with conflicting conclusions (see Table 3). Mitchell et al ${ }^{[66]}$ reported that using a SUV ${ }_{\max }$ cutoff value of 5.0 resulted in $60 \%$ sensitivity and $91 \%$ specificity for detection of malignancy, while Boeckmann et al. ${ }^{[67]}$ proposed a cutoff value of 4.2. Some reports noted a significant difference in $S_{U V} V_{\max }$ between malignant and benign lesions (albeit frequently with substantial overlap), while others showed no difference at all. Recall that benign and malignant oncocytic/Hürthle cell lesions are known to exhibit high FDG-avidity due to an intrinsic mitochondrial defect resulting in inefficient glucose metabolism ${ }^{[22,23]}$.

Small tumors, including many thyroid incidentalomas, may not be accurately quantified on PET imaging due to the partial-volume effect ${ }^{[68]}$. It is generally thought that the limit of resolution for PET/CT uptake is 5-8 $\mathrm{mm}$, although the partial volume effect may impact SUV values in lesions measuring 2 to 3 times the spatial resolution. Measures such as metabolic tumor volume (MTV) have attempted to correct for this limitation by accounting for volume, which may allow greater accuracy in the assessment of metabolic activity and thus the risk of malignancy. Unfortunately, data regarding these parameters remains inconclusive in their ability to discriminate benign from malignant thyroid incidentalomas. A study by Ceriani et al. ${ }^{[25]}$ evaluated functional PET-derived measures and found that malignant lesions had significantly higher values of MTV, total lesion glycolysis $\left(\mathrm{TLG}=\mathrm{MTV} \times \mathrm{SUV}_{\text {mean }}\right), \mathrm{SUV}_{\text {max }}, \mathrm{SUV}_{\text {mean }}$, and SUV ${ }_{\text {peak. }}$ Of these, TLG was the most useful parameter as it correctly identified $79 \%$ of lesions (univariate logistic regression, $P<0.0001)$.

The study by Ceriani et al.$^{[25]}$ also employed radiomic analysis of these lesions, using quantitative data from medical imaging to glean additional information such as shape and texture analysis. A multivariate stepwise logistic regression analysis found that TLG, $\mathrm{SUV}_{\max }$, and shape sphericity remained significant $(P<0.0001)$. All triple-positive tumors were found to be malignant, while $93 \%$ of triple-negative lesions were benign. A recent study by Aksu et al. ${ }^{[69]}$ supports these findings with the development of a predictive model combining

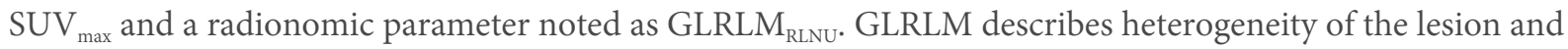
was found to have the highest AUC value on ROC analysis. The resulting model was found to have a sensitivity and specificity of $75 \%$ and $81.8 \%$, respectively. Other studies support the utility of these measures 
Table 2. Types of malignancies diagnosed in PET-detected thyroid incidentalomas by pattern of uptake

\begin{tabular}{|c|c|c|c|c|c|c|c|}
\hline Authors & $\begin{array}{l}\text { \#PET/CT } \\
\text { scans }\end{array}$ & $\begin{array}{l}\text { FDG uptake } \\
\text { pattern }\end{array}$ & Differentiated & Medullary & Anaplastic & Lymphoma & Metastasis \\
\hline Ceriani et al. ${ }^{[25]}$ & 12,652 & Focal & 24 & 1 & 1 & 1 & $\begin{array}{l}3 \text { (sarcoma, renal, } \\
\text { esophageal) }\end{array}$ \\
\hline Beck et al. ${ }^{[40]}$ & 35,124 & Focal & 48 & 0 & 0 & 2 & 9 \\
\hline Gedberg et al. ${ }^{[26]}$ & 2451 & Focal & 9 & 1 & 0 & 0 & 0 \\
\hline Ozderya et al. ${ }^{[42]}$ & 6873 & Focal & 23 & 1 & 0 & 0 & 3 (lung 2, esophagus) \\
\hline Makis et al. ${ }^{[43]}$ & 7252 & Focal & 12 & 0 & 0 & 1 & 1 (renal) \\
\hline Kim et al. ${ }^{[24]}$ & 18,172 & Focal & 51 & 0 & 0 & 0 & 0 \\
\hline Chun et al. ${ }^{[29]}$ & 2584 & Focal & 14 & 0 & 0 & 0 & 1 (SCC esophagus) \\
\hline Brindle et al. ${ }^{[33]}$ & 7221 & Focal & 6 & 0 & 0 & 1 & 0 \\
\hline Lee et al. ${ }^{[30]}$ & 2368 & Focal & 8 & 0 & 1 & 0 & $\begin{array}{l}2 \text { (melanoma, } \\
\text { adenocarcinoma) }\end{array}$ \\
\hline Nishimori et al. ${ }^{[18]}$ & 6457 & Focal & 9 & 0 & 0 & 0 & 0 \\
\hline Chen et al. ${ }^{[45]}$ & 2594 & Focal & 5 & 0 & 0 & 0 & 2 (H\&N SCC, NHL) \\
\hline Ishimori et al. ${ }^{[8]}$ & 1912 & Diffuse & 6 & 0 & 0 & 0 & 0 \\
\hline Kurata et al. ${ }^{[46]}$ & 1626 & $\begin{array}{l}\text { Diffuse } \\
\text { Diffuse }+ \text { focal }\end{array}$ & $\begin{array}{l}1 \\
2\end{array}$ & $\begin{array}{l}0 \\
0\end{array}$ & $\begin{array}{l}0 \\
0\end{array}$ & $\begin{array}{l}0 \\
0\end{array}$ & $\begin{array}{l}0 \\
0\end{array}$ \\
\hline Choi et al. ${ }^{[16]}$ & 1763 & Focal & 16 & 0 & 0 & 1 & 1 (esophageal SCC) \\
\hline Cumulative & 101,797 & & 234 & 3 & 2 & 6 & 22 \\
\hline
\end{tabular}

"Number of PET/CT scans.

Table 3. SUV $\mathbf{m}_{\max }$ values in benign versus malignant PET-detected thyroid incidentalomas

\begin{tabular}{llll}
\hline Authors & Benign SUV $_{\max }$ & Malignant SUV $_{\max }$ & P value \\
\hline Ceriani et al. $^{[25]}$ & 6.71 & 10.81 & $0.0146^{\mathrm{a}}$ \\
Ozderya et al. $^{[42]}$ & 6.1 & 11.3 & $0.01^{\mathrm{a}}$ \\
Sencan Eren et al. $^{[35]}$ & 4.6 & 8.8 & $<0.05$ \\
Chun et al. $^{[29]}$ & 2.8 & 4.7 & 0.001 \\
Brindle et al. $^{[33]}$ & 5.4 & 9.9 & $<0.05^{\mathrm{a}}$ \\
Lee et al. $^{[30]}$ & 3.62 & 5.47 & 0.126 \\
Nishimori et al. $^{[18]}$ & 5.2 & 5.8 & 0.36 \\
Kang et al. $^{[44]}$ & 3.56 & 6.32 & $<0.05$ \\
Chen et al. $^{[45]}$ & 2.9 & 4.0 & $>0.05$ \\
Choi et al. $^{[16]}$ & 6.7 & 10.7 & $<0.05$ \\
\hline
\end{tabular}

Due to heterogeneity of reported data (mean, median, range, SD), SUV max values are expressed as mean or median alone with median indicated by ${ }^{\text {a }}$.

to predict malignancy ${ }^{[31,70-72]}$. In opposition, other studies have shown no significant relationship between these indices and malignancy risk ${ }^{[73-76]}$. For now, the limited availability of these assessments may preclude the practical application of these parameters.

\section{Alternative radiotracer imaging}

FDG-PET/CT imaging accounts for most PET-identified thyroid incidentalomas, but this is increasingly recognized on other forms of functional imaging such as ${ }^{68} \mathrm{Ga}$-DOTATATE, ${ }^{68} \mathrm{Ga}$ PSMA, and ${ }^{18} \mathrm{~F}-$ or ${ }^{11} \mathrm{C}$ choline PET/CT scans. 
${ }^{68} \mathrm{Ga}$-DOTA PET/CT imaging is evolving as a method to evaluate and monitor neuroendocrine tumors expressing somatostatin receptors with a sensitivity and specificity as high as $96 \%$ and $100 \%$, respectively ${ }^{[77,78]}$. Multiple ${ }^{68} \mathrm{Ga}$-DOTA peptides have been studied that have a variable affinity for somatostatin receptor subtypes ${ }^{[79]} \cdot{ }^{68} \mathrm{Ga}$ - and ${ }^{64} \mathrm{Cu}$-DOTATATE are currently the only peptides clinically approved by the FDA in the USA for PET imaging. Physiologic uptake has been noted in the pituitary, thyroid, spleen, liver, adrenal glands, head of the pancreas, and urinary tract ${ }^{[80]}$. Normal thyroid tissue expressed somatostatin transmembrane receptors (SSTR), typically resulting in very low, diffuse uptake ${ }^{[88]}$. High SSTR2 expression has been noted in differentiated thyroid cancers and benign thyroid conditions ${ }^{[81]}$, but it is unclear if this uptake pattern varies from baseline physiologic uptake. Furthermore, activated lymphocytes are known to express SSTR. Thus benign inflammatory conditions such as thyroiditis, trauma, or surgery may induce abnormal uptake ${ }^{[80]}$. Importantly, medullary thyroid cancers would be expected to be highlighted on ${ }^{68} \mathrm{Ga}$-DOTATATE PET/CTs. However low or variable SSTR expression may give falsenegative results ${ }^{[80]}$. These scans are also subject to spatial resolution limitations. Studies have shown a $4.1 \%$ $11 \%$ rate of detection of thyroid incidentalomas on this imaging ${ }^{[47,82]}$, with an average of $2.6 \%$ (0.5\%-2.9\%) showing diffuse uptake. A study by Nockel et al. ${ }^{[4]}$ evaluated $237{ }^{68} \mathrm{Ga}$-DOTATATE scans to assess the uptake patterns in the thyroid gland. Abnormal thyroid uptake was noted in $11 \%$ (26 of 237), with 14 displaying focal uptake and 12 with a diffuse pattern. Three of the focal lesions were found to be differentiated thyroid cancers (21.4\% of focal incidentalomas). No significant difference was noted in $\mathrm{SUV}_{\max }$ values between benign and malignant lesions.

A recent study by Kohlenberg et al ${ }^{[83]}$ assessed thyroid lesions with focal ${ }^{68}$ Ga-DOTATATE PET/CT uptake, which was detected in $4.9 \%$ of scans (94 of 1927). Notably, four patients were imaged for the staging of a known medullary thyroid cancer. Five patients (one multifocal) were diagnosed with medullary thyroid cancer, one of which was discovered incidentally due to this imaging. As expected, the baseline calcitonin levels were quite elevated in MTC patients (median $1156 \mathrm{pg} / \mathrm{mL}$ ), while this data was limited in other patients. The 2015 American Thyroid Association guidelines do not recommend assessment of calcitonin in patients with thyroid nodules; however it certainly seems reasonable to consider it in patients with ${ }^{68} \mathrm{Ga}$ DOTATATE avidity. In addition to commonly reported semiquantitative measures of PET avidity such as $\mathrm{SUV}_{\max }$, focal thyroid lesions were also graded relative to normal tissues as internal controls. Two-thirds of MTC nodules were found to have relative ${ }^{68} \mathrm{Ga}$-DOTATATE avidity greater than that of the liver, which has previously been proposed as a favorable target for peptide receptor radionuclide therapy ${ }^{[84]}$.

${ }^{68} \mathrm{Ga}$-PSMA imaging is a promising tool increasingly used to stage and monitor prostate cancer by binding prostate-specific membrane antigen (PSMA) ${ }^{[48]}$. PSMA is expressed in normal prostate epithelium and highly expressed in prostate carcinoma. Expression of PSMA has been identified in the neovasculature of several other solid tumor types, including thyroid carcinomas, with strong staining noted in classical PTC, follicular thyroid carcinoma, and iodine-refractory cancers. All evaluated metastatic lesions exhibited PSMA expression compared to only $67 \%$ of lymph node metastases ${ }^{[85]}$. Furthermore, in a study of 10 patients with metastatic differentiated thyroid cancer, ${ }^{68} \mathrm{Ga}$-PSMA PET/CT identified 30 of 32 metastatic lesions ${ }^{[86]}$. These findings may advocate for use of this imaging for evaluation of suspected metastatic disease, particularly in radioiodine-refractory tumors.

Incidental ${ }^{68} \mathrm{Ga}-\mathrm{PSMA}$ thyroidal uptake is rare, the literature being punctuated mostly by single case reports. In a systematic review published in June 2019, Bertagna et al. ${ }^{[87]}$ collected a total of 23 cases of PSMA thyroid incidentaloma from 12 papers. Among these 23 patients, malignancy was documented in 6:5 primary thyroid (4 papillary thyroid carcinoma, one follicular thyroid carcinoma) and one metastasis from renal cell carcinoma. 
More recently, Gossili et al ${ }^{[88]}$ reported on their study of 341 patients with prostate cancer who had undergone ${ }^{68} \mathrm{Ga}$-PSMA PET/CT scanning, identifying 13 patients (4\%) with incidental increased thyroid uptake. The pattern of uptake was focal in seven, diffuse in five and diffuse-plus-focal in one. Malignancy was confirmed in 2 patients $(2 / 13,15 \%)$, and both displayed focal uptake. This paper was the subject of a commentary in Clinical Thyroidology by Santhanam and Cooper ${ }^{[89]}$ who noted the lack of sensitivity and specificity of PSMA-based thyroid imaging but enunciated on some of the potential benefits of detecting neovasculature in advanced metastatic radioiodine refractory thyroid cancer. They also recommended further investigations in patients found to have focal thyroidal uptake on PSMA-based PET imaging, namely thyroid ultrasound and biopsy. It is very likely that the true prevalence of PSMA-PETomas is higher since the present application of this imaging modality is for prostate cancer, thereby excluding female patients who are known to have an incidence of thyroid disorders ${ }^{[87]}$.

Radiolabeled choline $\left({ }^{18} \mathrm{~F}\right.$ or $\left.{ }^{11} \mathrm{C}\right)$ is another radiopharmaceutical with utility in imaging several solid tumors ${ }^{[0,91]}$, including potential for imaging parathyroid adenomas and hyperplasia ${ }^{[92]}$. Choline is a precursor to the phosphatidylcholine that comprises much of the cellular membrane and is internalized into the cell by choline kinase enzymes ${ }^{\left[{ }^{33}\right]}$. Increased uptake is noted in conditions with high proliferative rates. There are now reports of incidental thyroid uptake on radiolabelled choline PET/CT scans, mostly as case reports. In a retrospective analysis by Ruiz-Esponda et al.${ }^{[94]}$, only 30 thyroid incidentalomas were identified in a pool of 1197 radiolabelled choline PET/CT scans (2.5\%). Of the 15 patients that underwent diagnostic FNAC only one malignancy was identified, indicating that incidental thyroid lesions detected by this method may have a lower likelihood of malignancy than those detected by FDG-PET/CT.

\section{MUTATION ANALYSIS}

Mutation analysis has garnered significant traction in recent years across various cancers as a method to improve the characterization of tumors and associated prognosis. $B R A F^{V 600 E}$ is the commonest mutation encountered in adults with thyroid cancer, occurring in close to $50 \%$ of patients with papillary thyroid carcinoma ${ }^{[95]}$. Studies have shown that a BRAF mutation in papillary thyroid cancer is associated with worse outcomes ${ }^{[96,97]}$, commonly reported as a higher stage at diagnosis and more frequent distant metastases ${ }^{[88]}$. A higher risk of death has also been described with BRAF-mutated thyroid cancers, on the order of 2.66-fold higher ${ }^{[99]}$. It has been reported that male gender is a robust independent risk factor for PTC-specific mortality in $\mathrm{BRAF}^{\mathrm{V} 600 \mathrm{E}}$ patients but not in wild-type BRAF patients ${ }^{[100]}$. Moreover, these same authors identified age-associated mortality risk in PTC as dependent on BRAF status ${ }^{[101]}$. In a study comparing PETdetected papillary thyroid cancers to conventionally detected controls, Beck et al. ${ }^{[40]}$ described a higher rate of BRAF mutations in the PET-detected cohort $(78 \% v s .41 \%, P=0.05)$. In this report, the PET-detected cancers were more commonly found in males $(54 \% v s .26 \%, P=0.003)$ and higher stages (stage III $24 \% v s$. $12 \%$, stage IV $7 \% v \mathcal{~ v . ~} 0 \%, P=0.05)$. $B R A F^{V 600 E}$ mutation is associated with increased expression of glucose transporters (GLUT-1) in papillary thyroid cancers ${ }^{[102]}$, which may be responsible for the higher proportion of BRAF mutations in PET-detected cancers. In agreement with this, several studies have shown significantly higher $\mathrm{SUV}_{\text {max }}$ values in BRAF-mutated papillary thyroid cancers versus their BRAF-wild type counterparts ${ }^{[42,103,104]}$.

GLUT transporter expression was also noted to be elevated in thyroid incidentalomas exhibiting loss of the oncosuppressor gene $P T E N^{[105]}$. It was later confirmed by the same group that lack of PTEN expression in thyroid cancer cells was responsible for GLUT-1 upregulation and glucose uptake ${ }^{[106]}$. Aggressive, poorly differentiated thyroid cancers have higher levels of GLUT-1 expression ${ }^{[20,107,108]}$, which is the predominant isoform noted to be over-expressed with loss of PTEN expression ${ }^{[105]}$. Increased expression of GLUT proteins would be expected to correlate with increased cellular glucose, and thus FDG, uptake cancers 
cells $^{[108,109]}$. This increased expression of GLUT transporters in both BRAF and PTEN mutated phenotypes may give credence to the observation of PET-detected thyroid incidentalomas exhibiting more aggressive behavior. Notably, in a study of malignant PET-detected thyroid lesions not selected for PTEN loss by Kim et al. ${ }^{[110]}$, there was overall a low degree of GLUT-1 and GLUT-3 expression but a high level of VEGF expression. Consistent results were reported by Ohba et al ${ }^{[111]}$ in a study of benign PET-detected thyroid incidentalomas that were found to have a higher degree of vascularity than benign thyroid nodules not exhibiting FDG uptake.

Mutations in the $p 53$ tumor suppressor gene are exhibited in nearly 50\% of all cancers yet are identified in only $10 \%$ of thyroid cancers ${ }^{[112]}$. In a retrospective study of patients with PET-detected thyroid cancers, $86 \%$ of those that underwent operation were found to express p53 mutations, and this was not related to $\mathrm{SUV}_{\max }{ }^{[42]}$. The significance of this finding is not yet known.

Fine needle aspiration yields indeterminate results in 15\%-30\% of patient ${ }^{[113]}$, which may persist after repeat FNAC. Molecular diagnostic tests such as Afirma ${ }^{[114]}$, ThyroSeq ${ }^{[15,116]}$, and ThyGeNEXT/ThyraMIR ${ }^{[117]}$ have been developed to differentiate this indeterminate category, yet the utility of these tests is unclear in a population selected for FDG avidity. In a study utilizing Afirma Gene Expression Classifier (GEC) or Genome Sequence Classifier (GSC) profiling in thyroid PETomas with indeterminate cytology, Endo et al.$^{[118]}$ found that $28.6 \%$ of these nodules were predicted malignant per Afirma GEC/GSC compared to a $36.4 \%$ rate of malignancy in histologically proven nodules. The benign call rate (BCR) was significantly higher in patients with low-risk ultrasound features (83.3\%) vs. 29\% in intermediate- or high-risk ultrasound features $(P=0.026)$. The higher BCR with Afirma GSC $(64 \%)$ may indicate that surgical intervention can be safely avoided or delayed in these patients.

\section{MANAGEMENT RECOMMENDATIONS}

Clinical guidelines for the management of thyroid nodules in the general population are well established $^{[119,120]}$. Given that most PET/CT imaging is pursued to evaluate another malignancy that may limit life expectancy, it is difficult to determine if these guidelines should apply to this population. Thyroid cancer is associated with an excellent prognosis, with overall 10-year survival rates of differentiated thyroid cancers exceeding $90 \%-95 \%{ }^{[121]}$. For example, in patients that underwent cytologic diagnosis of an incidental thyroid cancer, the risk of death from thyroid cancer was $<1 \%{ }^{[32]}$. Studies of active surveillance of low-risk papillary microcarcinomas (cytologically confirmed PTC with nodule diameter $\leq 1 \mathrm{~cm}$ without high-risk features) have shown safety with this approach. In this review, only $7 \%-8 \%$ of observed nodules increased in size, and there were no instances of recurrence or death following salvage surgery ${ }^{[122]}$. Contrary to this, Are et al.$^{[5]}$ suggested that incidentalomas are associated with a poorer prognosis due to a higher rate of unfavorable pathologic features such as tall cell variant, poor differentiation, and extrathyroidal extension. Data from our institution identified a $30 \%$ rate of poor prognostic features in these patients ${ }^{[18]}$.

Although most thyroid carcinomas are associated with an excellent prognosis, it does seem prudent that each incidentally discovered thyroid lesion be carefully evaluated for risk factors that may elucidate the relevance of such lesions. Review of prior images should be conducted to evaluate the evolution of the noted lesion over time ${ }^{[123]}$. In addition to the previously mentioned features, PET scans may reveal signs of lateral lymph node metastases ${ }^{[24]}$, which is associated with a poorer prognosis ${ }^{[124-126]}$ and is key for developing adequate surgical plans should this route be pursued ${ }^{[127]}$. Other features contributing to malignancy risk include younger age ${ }^{[19,128]}$, male gender ${ }^{[128,129]}$, childhood radiation exposure ${ }^{[130,131]}$, and family history of thyroid cancer ${ }^{[132]}$. 
Current clinical guidelines recommend further investigation, including FNAC, to evaluate all PETidentified thyroid incidentalomas greater than $1 \mathrm{~cm}$ in diameter ${ }^{[119]}$. However, a study utilizing SEER data found that only tumor size $>2.5 \mathrm{~cm}$ was associated with an increased mortality ${ }^{[133]}$. Another populationbased study found size $>2 \mathrm{~cm}$, microcalcifications, and solid composition related to increased malignancy risk $^{[134]}$. The risk of cancer in solid lesions has been reported at $13 \%$ compared to $4 \%$ for mixed solid/cystic lesions ${ }^{[135]}$.

Ultrasound has been the mainstay of imaging thyroid nodules. Several risk stratification systems (ACR-, EU-, and K-TIRADS) have been developed, however, it is open for debate if these systems are applicable to PET-detected thyroid incidentalomas. Previous investigators have proposed that these lesions have a greater likelihood of high-risk features ${ }^{[18,55]}$, which may make these stratifications schemes unreliable. However, a reliable stratification schema is essential as it is impractical to require FNAC of all PET-detected thyroid incidentalomas. Trimboli et al. ${ }^{[136]}$ examined the ability of EU-TIRADS to appropriately stratify focal PETdetected thyroid incidentalomas with histologic diagnoses or scintigraphic confirmation of an autonomously functioning thyroid nodule. Of the 13 confirmed malignancies included in this study, 11 were categorized as EU-TIRADS 5, 1 as EU-TIRADS 4, and 1 as EU-TIRADS 3. SUV max $_{\text {ax }}$ and SUV max $_{\text {ratio }}$ were also found to be significantly higher in the cancer population, with the most accurate cut-off values determined as $>7.1$ and $>3.65$, respectively. The presence of one of these risk factors $\left(\mathrm{SUV}_{\max }>7.1, \mathrm{SUV}_{\max }\right.$ ratio $>3.65$, or EU-TIRADS 5) detected 12 of 13 cancers (92\% sensitivity) while the absence of these features detected 34 or 35 benign lesions (97\% specificity). This data was recently expanded to evaluate ACRTIRADS and K-TIRADS systems in addition to EU-TIRADS ${ }^{[137]}$. EU-TIRADS and K-TIRADS both showed $100 \%$ specificity and NPV, while the sensitivity of ACR-TIRADS was $81 \%$. This resulted in recommendations to obtain FNAC in $48 \%$ of patients according to ACR-TIRADS, $61 \%$ per EU-TIRADS, and $75 \%$ per K-TIRADS. Given the higher likelihood of cancer in this population, EU-TIRADS and KTIRADS were advocated as the preferred stratification tools due to the greater number of FNAC recommended.

In debating the issues of appropriate management, those with a known or suspected underlying cancer or life-limiting comorbidity must be considered separately from an asymptomatic, healthy patient. An otherwise healthy patient should receive the full measure of workup and treatment as indicated by current guidelines. In patients with life-limiting malignancies or comorbidities should be approached with further judiciousness. Thoughtful consideration of patient factors (age, comorbidities, quality of life), underlying malignancy (prognosis, required treatment), and local radiologic features are mandatory ${ }^{[32]}$. The risk of intervention must be weighed against the potential benefits. Further evaluation with dedicated ultrasound imaging incites little risk, and FNAC should be considered if appropriate per TIRADS recommendations. Given the diversity of cancers diagnosed in these patients (see Table 2), it does seem prudent to biopsy these lesions where possible. Confirmation of metastasis or thyroid lymphoma would be expected to drive a change in treatment approach. Diagnosis of a papillary thyroid cancer may prompt consideration of active surveillance due to the generally indolent nature of this condition, or surgical management if the patient's condition permits. Patient status should be continually assessed with re-evaluation of the management plan, and it is certainly plausible to consider surveillance of a thyroid nodule during treatment of the index cancer with conversion to active management as the status improves.

\section{Summary of recommendations}

1. Assess the patient's clinical condition, considering the index cancer, comorbidities, and frailty. 
a. If unacceptable for further intervention, reassess for possible intervention as status changes.

2. For those with focal PET/CT thyroid avidity that is amenable to further intervention, neck ultrasound should be obtained, with FNAC pursued based on TIRADS guidelines.

3. In thyroid incidentalomas discovered on ${ }^{68} \mathrm{Ga}$-DOTATATE PET/CT, consider obtaining a baseline calcitonin level.

4. Active surveillance of a well-differentiated thyroid carcinoma can be considered during active management of the index malignancy; however, it should be acknowledged that some PET-detected thyroid incidentalomas may represent more aggressive malignancies.

\section{CONCLUSION}

In conclusion, the incidence of PET-detected thyroid incidentalomas can only be expected to increase as further technological advancements are made. In the current state, no imaging features or patterns of uptake can definitively discern benign from malignant lesions. Clinicians must employ the art of medicine and carefully balance the risks and benefits of pursuing further workup and management while taking into account the underlying condition and expectations of the patient. As more developments are attained in research and technology, we will further refine this paradigm and enhance our ability to provide the best care for life.

\section{DECLARATIONS}

Authors' contributions

Made significant contributions to the compilation of this manuscript: Corn S, Mitmaker E, Tabah R, Ciarallo A, How J

\section{Availability of data and materials}

Not applicable.

\section{Financial support and sponsorship}

None.

\section{Conflicts of interest}

All authors declared that there are no conflicts of interest.

\section{Ethical approval and consent to participate}

Not applicable.

\section{Consent for publication}

Not applicable.

\section{Copyright}

(c) The Author(s) 2021.

\section{REFERENCES}

1. Smith-Bindman R, Kwan ML, Marlow EC, et al. Trends in use of medical imaging in US health care systems and in Ontario, Canada, 2000-2016. JAMA 2019;322:843-56. DOI PubMed PMC

2. O'Sullivan JW, Muntinga T, Grigg S, Ioannidis JPA. Prevalence and outcomes of incidental imaging findings: umbrella review. BMJ 2018;361:k2387. DOI PubMed PMC

3. WARBURG O. On the origin of cancer cells. Science 1956;123:309-14. DOI PubMed 
4. Rosenbaum SJ, Lind T, Antoch G, Bockisch A. False-positive FDG PET uptake-the role of PET/CT. Eur Radiol 2006;16:1054-65. DOI PubMed

5. Albano D, Treglia G, Giovanella L, Giubbini R, Bertagna F. Detection of thyroiditis on PET/CT imaging: a systematic review. Hormones (Athens) 2020;19:341-9. DOI PubMed

6. Zhuang H, Alavi A. 18-fluorodeoxyglucose positron emission tomographic imaging in the detection and monitoring of infection and inflammation. Semin Nucl Med 2002;32:47-59. DOI PubMed

7. Agress H Jr, Cooper BZ. Detection of clinically unexpected malignant and premalignant tumors with whole-body FDG PET: histopathologic comparison. Radiology 2004;230:417-22. DOI PubMed

8. Ishimori T, Patel PV, Wahl RL. Detection of unexpected additional primary malignancies with PET/CT. J Nucl Med 2005;46:752-7. PubMed

9. Dong C, Hemminki K. Second primary neoplasms among 53159 haematolymphoproliferative malignancy patients in Sweden, 19581996: a search for common mechanisms. Br J Cancer 2001;85:997-1005. DOI PubMed PMC

10. Ueno M, Muto T, Oya M, Ota H, Azekura K, Yamaguchi T. Multiple primary cancer: an experience at the Cancer Institute Hospital with special reference to colorectal cancer. Int J Clin Oncol 2003;8:162-7. DOI PubMed

11. Kang KW, Kim SK, Kang HS, et al. Prevalence and risk of cancer of focal thyroid incidentaloma identified by $18 \mathrm{~F}$ fluorodeoxyglucose positron emission tomography for metastasis evaluation and cancer screening in healthy subjects. $J$ Clin Endocrinol Metab 2003;88:4100-4. DOI PubMed

12. Yang Z, Shi W, Zhu B, et al. Prevalence and risk of cancer of thyroid incidentaloma identified by fluorine-18 fluorodeoxyglucose positron emission tomography/computed tomography. J Otolaryngol Head Neck Surg 2012;41:327-33. PubMed

13. Brander A, Viikinkoski P, Nickels J, Kivisaari L. Thyroid gland: US screening in a random adult population. Radiology 1991;181:683-7. DOI PubMed

14. Bartolotta TV, Midiri M, Runza G, et al. Incidentally discovered thyroid nodules: incidence, and greyscale and colour Doppler pattern in an adult population screened by real-time compound spatial sonography. Radiol Med 2006;111:989-98. DOI PubMed

15. Moon JH, Hyun MK, Lee JY, et al. Prevalence of thyroid nodules and their associated clinical parameters: a large-scale, multicenterbased health checkup study. Korean J Intern Med 2018;33:753-62. DOI PubMed PMC

16. Choi JY, Lee KS, Kim HJ, et al. , Focal thyroid lesions incidentally identified by integrated 18F-FDG PET/CT: clinical significance and improved characterization. J Nucl Med 2006;47:609-15. PubMed

17. Kang HW, No JH, Chung JH, et al. Prevalence, clinical and ultrasonographic characteristics of thyroid incidentalomas. Thyroid 2004;14:29-33. DOI PubMed

18. Nishimori H, Tabah R, Hickeson M, How J. Incidental thyroid "PETomas": clinical significance and novel description of the selfresolving variant of focal FDG-PET thyroid uptake. Can J Surg 2011;54:83-8. DOI PubMed PMC

19. Shetty SK, Maher MM, Hahn PF, Halpern EF, Aquino SL. Significance of incidental thyroid lesions detected on CT: correlation among CT, sonography, and pathology. AJR Am J Roentgenol 2006;187:1349-56. DOI PubMed

20. Hosaka Y, Tawata M, Kurihara A, Ohtaka M, Endo T, Onaya T. The regulation of two distinct glucose transporter (GLUT1 and GLUT4) gene expressions in cultured rat thyroid cells by thyrotropin. Endocrinology 1992;131:159-65. DOI PubMed

21. Gould GW, Thomas HM, Jess TJ, Bell GI. Expression of human glucose transporters in Xenopus oocytes: kinetic characterization and substrate specificities of the erythrocyte, liver, and brain isoforms. Biochemistry 1991;30:5139-45. DOI PubMed

22. Pattison DA, Hofman MS. Role of fluorodeoxyglucose PET/computed tomography in targeted radionuclide therapy for endocrine malignancies. PET Clin 2015;10:461-76. DOI PubMed

23. Gasparre G, Porcelli AM, Bonora E, et al. Disruptive mitochondrial DNA mutations in complex I subunits are markers of oncocytic phenotype in thyroid tumors. Proc Natl Acad Sci U S A 2007;104:9001-6. DOI PubMed PMC

24. Kim BH, Kim SJ, Kim K, et al. High metabolic tumor volume and total lesion glycolysis are associated with lateral lymph node metastasis in patients with incidentally detected thyroid carcinoma. Ann Nucl Med 2015;29:721-9. DOI PubMed PMC

25. Ceriani L, Milan L, Virili C, et al. Radiomics analysis of $\left[{ }^{18} \mathrm{~F}\right]$-Fluorodeoxyglucose-avid thyroid incidentalomas improves risk stratification and selection for clinical assessment. Thyroid 2021;31:88-95. DOI PubMed

26. Gedberg N, Karmisholt J, Gade M, Fisker RV, Iyer V, Petersen LJ. The frequency of focal thyroid incidental findings and risk of malignancy detected by $18 \mathrm{~F}$-fluorodeoxyglucose positron emission tomography in an iodine deficient population. Diagnostics (Basel) 2018;8:46. DOI PubMed PMC

27. Hassan A, Riaz S, Zafar W. Fluorine-18 fluorodeoxyglucose avid thyroid incidentalomas on PET/CT scan in cancer patients: how sinister are they? Nucl Med Commun 2016;37:1069-73. DOI PubMed

28. Even-Sapir E, Lerman H, Gutman M, et al. The presentation of malignant tumours and pre-malignant lesions incidentally found on PET-CT. Eur J Nucl Med Mol Imaging 2006;33:541-52. DOI PubMed

29. Chun AR, Jo HM, Lee SH, et al. Risk of malignancy in thyroid incidentalomas identified by fluorodeoxyglucose-positron emission tomography. Endocrinol Metab (Seoul) 2015;30:71-7. DOI PubMed PMC

30. Lee S, Park T, Park S, et al. The clinical role of dual-time-point (18)F-FDG PET/CT in differential diagnosis of the thyroid incidentaloma. Nucl Med Mol Imaging 2014;48:121-9. DOI PubMed PMC

31. Soelberg KK, Bonnema SJ, Brix TH, Hegedüs L. Risk of malignancy in thyroid incidentalomas detected by $18 \mathrm{~F}$-fluorodeoxyglucose positron emission tomography: a systematic review. Thyroid 2012;22:918-25. DOI PubMed

32. Pattison DA, Bozin M, Gorelik A, Hofman MS, Hicks RJ, Skandarajah A. ${ }^{18}$ F-FDG-avid thyroid incidentalomas: the importance of contextual interpretation. J Nucl Med 2018;59:749-55. DOI PubMed

33. Brindle R, Mullan D, Yap BK, Gandhi A. Thyroid incidentalomas discovered on positron emission tomography CT scanning - 
malignancy rate and significance of standardised uptake values. Eur J Surg Oncol 2014;40:1528-32. DOI PubMed

34. Karantanis D, Bogsrud TV, Wiseman GA, et al. Clinical significance of diffusely increased 18F-FDG uptake in the thyroid gland. $J$ Nucl Med 2007;48:896-901. DOI PubMed

35. Şencan Eren M, Özdoğan Ö, Gedik A, et al. The incidence of 18F-FDG PET/CT thyroid incidentalomas andthe prevalence of malignancy: a prospective study. Turk J Med Sci 2016;46:840-7. DOI PubMed

36. Jamsek J, Zagar I, Gaberscek S, Grmek M. Thyroid lesions incidentally detected by (18)F-FDG PET-CT - a two centre retrospective study. Radiol Oncol 2015;49:121-7. DOI PubMed PMC

37. Salvatori M, Melis L, Castaldi P, et al. Clinical significance of focal and diffuse thyroid diseases identified by (18)Ffluorodeoxyglucose positron emission tomography. Biomed Pharmacother 2007;61:488-93. DOI PubMed

38. Bae JS, Chae BJ, Park WC, et al. Incidental thyroid lesions detected by FDG-PET/CT: prevalence and risk of thyroid cancer. World $J$ Surg Oncol 2009;7:63. DOI PubMed PMC

39. Katz SC, Shaha A. PET-associated incidental neoplasms of the thyroid. J Am Coll Surg 2008;207:259-64. DOI PubMed

40. Beck T, Zhang N, Shah A, Khoncarly S, McHenry C, Jin J. Thyroid cancer identified after positron emission tomography (PET) shows aggressive histopathology. J Surg Res 2021;260:245-50. DOI PubMed

41. Kim YH, Chang Y, Kim Y, et al. Diffusely increased ${ }^{18}$ F-FDG uptake in the thyroid gland and risk of thyroid dysfunction: a cohort study. J Clin Med 2019;8:443. DOI PubMed PMC

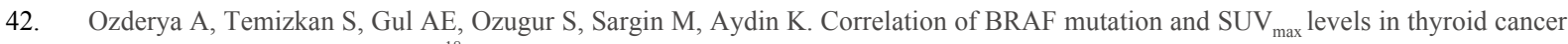
patients incidentally detected in ${ }^{18} \mathrm{~F}$-fluorodeoxyglucose positron emission tomography. Endocrine 2017;55:215-22. DOI PubMed

43. Makis W, Ciarallo A. Thyroid incidentalomas on ${ }^{18}$ F-FDG PET/CT: clinical significance and controversies. Mol Imaging Radionucl Ther 2017;26:93-100. DOI PubMed PMC

44. Kang BJ, O JH, Baik JH, Jung SL, Park YH, Chung SK. Incidental thyroid uptake on F-18 FDG PET/CT: correlation with ultrasonography and pathology. Ann Nucl Med 2009;23:729-37. DOI PubMed

45. Chen W, Parsons M, Torigian DA, Zhuang H, Alavi A. Evaluation of thyroid FDG uptake incidentally identified on FDG-PET/CT imaging. Nucl Med Commun 2009;30:240-4. DOI PubMed

46. Kurata S, Ishibashi M, Hiromatsu Y, et al. Diffuse and diffuse-plus-focal uptake in the thyroid gland identified by using FDG-PET: prevalence of thyroid cancer and Hashimoto's thyroiditis. Ann Nucl Med 2007;21:325-30. DOI PubMed

47. Nockel P, Millo C, Keutgen X, et al. The rate and clinical significance of incidental thyroid uptake as detected by gallium-68 DOTATATE positron emission tomography/computed tomography. Thyroid 2016;26:831-5. DOI PubMed PMC

48. Pagano L, Samà MT, Morani F, et al. Thyroid incidentaloma identified by $18 \mathrm{~F}$-fluorodeoxyglucose positron emission tomography with CT (FDG-PET/CT): clinical and pathological relevance. Clin Endocrinol (Oxf) 2011;75:528-34. DOI PubMed

49. Bertagna F, Treglia G, Piccardo A, et al. F18-FDG-PET/CT thyroid incidentalomas: a wide retrospective analysis in three Italian centres on the significance of focal uptake and SUV value. Endocrine 2013;43:678-85. DOI PubMed

50. Nilsson IL, Arnberg F, Zedenius J, Sundin A. Thyroid incidentaloma detected by fluorodeoxyglucose positron emission tomography/computed tomography: practical management algorithm. World J Surg 2011;35:2691-7. DOI PubMed

51. Asmar A, Simonsen L, Bülow J, Asmar M. [Work-up of thyroid incidentalomas identified by (18)F-fluorodeoxyglucose PET/CT]. Ugeskr Laeger 2017;179:V12160893. PubMed

52. Yasuda S, Shohtsu A, Ide M, et al. Chronic thyroiditis: diffuse uptake of FDG at PET. Radiology 1998;207:775-8. DOI PubMed

53. Cohen MS, Arslan N, Dehdashti F, et al. Risk of malignancy in thyroid incidentalomas identified by fluorodeoxyglucose-positron emission tomography. Surgery 2001;130:941-6. DOI PubMed

54. Kim TY, Kim WB, Ryu JS, Gong G, Hong SJ, Shong YK. 18F-fluorodeoxyglucose uptake in thyroid from positron emission tomogram (PET) for evaluation in cancer patients: high prevalence of malignancy in thyroid PET incidentaloma. Laryngoscope 2005;115:1074-8. DOI PubMed

55. Are C, Hsu JF, Schoder H, Shah JP, Larson SM, Shaha AR. FDG-PET detected thyroid incidentalomas: need for further investigation? Ann Surg Oncol 2007;14:239-47. DOI PubMed

56. Hollowell JG, Staehling NW, Flanders WD, et al. Serum TSH, T(4), and thyroid antibodies in the United States population (1988 to 1994): National Health and Nutrition Examination Survey (NHANES III). J Clin Endocrinol Metab 2002;87:489-99. DOI PubMed

57. Pruthi A, Choudhury PS, Gupta M, Taywade S. Does the intensity of diffuse thyroid gland uptake on F-18 fluorodeoxyglucose positron emission tomography/computed tomography scan predict the severity of hypothyroidism? Indian J Nucl Med 2015;30:16-20. DOI PubMed PMC

58. Kim SS, Kim SJ, Bae YT, et al. Factors associated with the development of new onset diffuse thyroid F18-fluorodeoxyglucose uptake after treatment of breast cancer in patients without a history of thyroid disease or thyroid dysfunction. Thyroid 2012;22:53-8. DOI PubMed

59. Langer JE, Khan A, Nisenbaum HL, et al. Sonographic appearance of focal thyroiditis. AJR Am J Roentgenol 2001;176:751-4. DOI PubMed

60. Hwang S, Shin DY, Kim EK, et al. Focal lymphocytic thyroiditis nodules share the features of papillary thyroid cancer on ultrasound. Yonsei Med J 2015;56:1338-44. DOI PubMed PMC

61. Thuillier P, Crouzeix G, Descourt R, Salaun PY, Abgral R. Progression of focal to diffuse thyroid uptake detected by 18 F-FDG PET/CT: malignant metastatic disease or benign thyroiditis? Clin Nucl Med 2018;43:e310-1. DOI PubMed

62. Poller DN, Megadmi H, Ward MJA, Trimboli P. Hürthle cells on fine-needle aspiration cytology are important for risk assessment of focally PET/CT FDG avid thyroid nodules. Cancers (Basel) 2020;12:3544. DOI PubMed PMC

63. Noone AM, Howlader N, Krapcho M, et al. SEER cancer statistics review, 1975-2015, National Cancer Institute. Bethesda, MD. 
Available from: https://seer.cancer.gov/csr/1975_2015/ [Last accessed on 3 Aug 2021].

64. Nayan S, Ramakrishna J, Gupta MK. The Proportion of malignancy in incidental thyroid lesions on 18-FDG PET study: a systematic review and meta-analysis. Otolaryngol Head Neck Surg 2014;151:190-200. DOI PubMed

65. Millare GG, Kwon M, Edeiken-Monroe BS, Debnam JM. ${ }^{18} \mathrm{~F}-\mathrm{PET} / \mathrm{CT}$ imaging of metastasis to the thyroid gland: imaging findings and effect on patient management. J Solid Tumors 2017;7:7-13. DOI PubMed PMC

66. Mitchell JC, Grant F, Evenson AR, Parker JA, Hasselgren PO, Parangi S. Preoperative evaluation of thyroid nodules with 18FDGPET/CT. Surgery 2005;138:1166-74; discussion 1174. DOI PubMed

67. Boeckmann J, Bartel T, Siegel E, Bodenner D, Stack BC Jr. Can the pathology of a thyroid nodule be determined by positron emission tomography uptake? Otolaryngol Head Neck Surg 2012;146:906-12. DOI PubMed

68. Soret M, Bacharach SL, Buvat I. Partial-volume effect in PET tumor imaging. J Nucl Med 2007;48:932-45. DOI PubMed

69. Aksu A, Karahan Şen NP, Acar E, Çapa Kaya G. Evaluating focal ${ }^{18}$ F-FDG uptake in thyroid gland with radiomics. Nucl Med Mol Imaging 2020;54:241-8. DOI PubMed PMC

70. Shi H, Yuan Z, Yuan Z, et al. Diagnostic value of volume-based fluorine-18-fluorodeoxyglucose PET/CT parameters for characterizing thyroid incidentaloma. Korean J Radiol 2018;19:342-51. DOI PubMed PMC

71. Kim BH, Kim SJ, Kim H, et al. Diagnostic value of metabolic tumor volume assessed by 18F-FDG PET/CT added to SUVmax for characterization of thyroid 18F-FDG incidentaloma. Nucl Med Commun 2013;34:868-76. DOI PubMed

72. Sollini M, Cozzi L, Pepe G, et al. $\left[{ }^{18} \mathrm{~F}\right] \mathrm{FDG}-\mathrm{PET} / \mathrm{CT}$ texture analysis in thyroid incidentalomas: preliminary results. Eur $J$ Hybrid Imaging 2017;1:3. DOI PubMed PMC

73. Bertagna F, Treglia G, Piccardo A, Giubbini R. Diagnostic and clinical significance of F-18-FDG-PET/CT thyroid incidentalomas. $J$ Clin Endocrinol Metab 2012;97:3866-75. DOI PubMed

74. Sager S, Vatankulu B, Sahin OE, et al. Clinical significance of standardized uptake values in thyroid incidentaloma discovered by F18 fluorodeoxyglucose positron emission tomography/computed tomography. J Cancer Res Ther 2018;14:989-93. DOI PubMed

75. Thuillier P, Bourhis D, Roudaut N, et al. Diagnostic Value of FDG PET-CT quantitative parameters and deauville-like 5 point-scale in predicting malignancy of focal thyroid incidentaloma. Front Med (Lausanne) 2019;6:24. DOI PubMed PMC

76. Ho TY, Liou MJ, Lin KJ, Yen TC. Prevalence and significance of thyroid uptake detected by 18F-FDG PET. Endocrine 2011;40:297-302. DOI PubMed

77. Yang J, Kan Y, Ge BH, Yuan L, Li C, Zhao W. Diagnostic role of Gallium-68 DOTATOC and Gallium-68 DOTATATE PET in patients with neuroendocrine tumors: a meta-analysis. Acta Radiol 2014;55:389-98. DOI PubMed

78. Druckenthaner M, Schwarzer C, Ensinger C, et al. Evidence for somatostatin receptor 2 in thyroid tissue. Regul Pept 2007;138:32-9. DOI PubMed

79. Prasad V, Ambrosini V, Alavi A, Fanti S, Baum RP. PET/CT in neuroendocrine tumors: evaluation of receptor status and metabolism. PET Clin 2008;3:355-79. DOI PubMed

80. Ambrosini V, Nanni C, Fanti S. The use of gallium-68 labeled somatostatin receptors in PET/CT imaging. PET Clin 2014;9:323-9. DOI PubMed

81. Atkinson H, England JA, Rafferty A, et al. Somatostatin receptor expression in thyroid disease. Int J Exp Pathol 2013;94:226-9. DOI PubMed PMC

82. Kunikowska J, Matyskiel R, Zemczak A, et al. How often do we see incidental 68Ga-DOTATATE thyroid uptake in PET/CT in patients with neuroendocrine tumours? Endokrynol Pol 2015;66:231-6. DOI PubMed

83. Kohlenberg JD, Panda A, Johnson GB, Castro MR. Radiologic and clinicopathologic characteristics of thyroid nodules with focal 68Ga-DOTATATE PET activity. Nucl Med Commun 2021;42:510-6. DOI PubMed

84. Beukhof CM, Brabander T, van Nederveen FH, et al. Peptide receptor radionuclide therapy in patients with medullary thyroid carcinoma: predictors and pitfalls. BMC Cancer 2019;19:325. DOI PubMed PMC

85. Moore M, Panjwani S, Mathew R, et al. Well-differentiated thyroid cancer neovasculature expresses prostate-specific membrane antigen-a possible novel therapeutic target. Endocr Pathol 2017;28:339-44. DOI PubMed

86. Verma P, Malhotra G, Agrawal R, Sonavane S, Meshram V, Asopa RV. Evidence of prostate-specific membrane antigen expression in metastatic differentiated thyroid cancer using 68Ga-PSMA-HBED-CC PET/CT. Clin Nucl Med 2018;43:e265-8. DOI PubMed

87. Bertagna F, Albano D, Giovanella L, et al. ${ }^{68}$ Ga-PSMA PET thyroid incidentalomas. Hormones (Athens) 2019;18:145-9. DOI PubMed

88. Gossili F, Petersen LJ, Zacho HD. The frequency of thyroid incidental findings and risk of malignancy detected by 68Ga-labeled prostate-specific membrane antigen PET/CT in prostate cancer. Hell J Nucl Med 2020;23:240-5. DOI PubMed

89. Santhanam P, Cooper D. How should we approach incidental thyroid nodules with Gallium-68 Prostate-Specific Membrane Antigen (PSMA) positivity? Clin Thyroidol 2021;33:87-91. DOI

90. Mertens K, Slaets D, Lambert B, Acou M, De Vos F, Goethals I. PET with (18)F-labelled choline-based tracers for tumour imaging: a review of the literature. Eur J Nucl Med Mol Imaging 2010;37:2188-93. DOI PubMed

91. Treglia G, Giovannini E, Di Franco D, et al. The role of positron emission tomography using carbon-11 and fluorine-18 choline in tumors other than prostate cancer: a systematic review. Ann Nucl Med 2012;26:451-61. DOI PubMed

92. Uslu-Beşli L, Sonmezoglu K, Teksoz S, et al. Performance of F-18 Fluorocholine PET/CT for detection of hyperfunctioning parathyroid tissue in patients with elevated parathyroid hormone levels and negative or discrepant results in conventional imaging. Korean J Radiol 2020;21:236-47. DOI PubMed PMC

93. Podo F. Tumour phospholipid metabolism. NMR Biomed 1999;12:413-39. DOI PubMed

94. Ruiz-Esponda RL, Dean DS. Clinical significance of incidental thyroid uptake on 11Ccholine PET/CT. Endo Rev 2014:35. DOI 
95. Xing M. BRAF mutation in thyroid cancer. Endocr Relat Cancer 2005;12:245-62. DOI PubMed

96. Elisei R, Ugolini C, Viola D, et al. BRAF(V600E) mutation and outcome of patients with papillary thyroid carcinoma: a 15-year median follow-up study. J Clin Endocrinol Metab 2008;93:3943-9. DOI PubMed

97. Tufano RP, Teixeira GV, Bishop J, Carson KA, Xing M. BRAF mutation in papillary thyroid cancer and its value in tailoring initial treatment: a systematic review and meta-analysis. Medicine (Baltimore) 2012;91:274-86. DOI PubMed

98. Cuccurullo V, Di Stasio GD, Cascini GL. PET/CT in thyroid cancer - the importance of BRAF mutations. Nucl Med Rev Cent East Eur 2020;23:97-102. DOI PubMed

99. Pak K, Suh S, Kim SJ, Kim IJ. Prognostic value of genetic mutations in thyroid cancer: a meta-analysis. Thyroid 2015;25:63-70. DOI PubMed

100. Wang F, Zhao S, Shen X, et al. BRAF V600E confers male sex disease-specific mortality risk in patients with papillary thyroid cancer. J Clin Oncol 2018;36:2787-95. DOI PubMed PMC

101. Shen X, Zhu G, Liu R, et al. Patient age-associated mortality risk is differentiated by BRAF V600E status in papillary thyroid cancer. J Clin Oncol 2018;36:438-45. DOI PubMed PMC

102. Durante C, Puxeddu E, Ferretti E, et al. BRAF mutations in papillary thyroid carcinomas inhibit genes involved in iodine metabolism. J Clin Endocrinol Metab 2007;92:2840-3. DOI PubMed

103. Chang JW, Park KW, Heo JH, et al. Relationship between ${ }^{18} \mathrm{~F}$-fluorodeoxyglucose accumulation and the BRAF ${ }^{\mathrm{V} 600 \mathrm{E}}$ mutation in papillary thyroid cancer. World J Surg 2018;42:114-22. DOI PubMed

104. Choi EK, Chong A, Ha JM, Jung CK, O JH, Kim SH. Clinicopathological characteristics including BRAF V600E mutation status and PET/CT findings in papillary thyroid carcinoma. Clin Endocrinol (Oxf) 2017;87:73-9. DOI PubMed

105. Morani F, Pagano L, Prodam F, Aimaretti G, Isidoro C. Loss of expression of the oncosuppressor PTEN in thyroid incidentalomas associates with GLUT1 plasmamembrane expression. Panminerva Med 2012;54:59-63. PubMed

106. Morani F, Phadngam S, Follo C, et al. PTEN regulates plasma membrane expression of glucose transporter 1 and glucose uptake in thyroid cancer cells. J Mol Endocrinol 2014;53:247-58. DOI PubMed

107. Samih N, Hovsepian S, Aouani A, Lombardo D, Fayet G. Glut-1 translocation in FRTL-5 thyroid cells: role of phosphatidylinositol 3-kinase and N-glycosylation. Endocrinology 2000;141:4146-55. DOI PubMed

108. Matsuzu K, Segade F, Wong M, Clark OH, Perrier ND, Bowden DW. Glucose transporters in the thyroid. Thyroid 2005;15:545-50. DOI PubMed

109. Matsuzu K, Segade F, Matsuzu U, Carter A, Bowden DW, Perrier ND. Differential expression of glucose transporters in normal and pathologic thyroid tissue. Thyroid 2004;14:806-12. DOI PubMed

110. Kim BH, Kim IJ, Kim SS, Kim SJ, Lee CH, Kim YK. Relationship between biological marker expression and fluorine-18 fluorodeoxyglucose uptake in incidentally detected thyroid cancer. Cancer Biother Radiopharm 2010;25:309-15. DOI PubMed

111. Ohba K, Sasaki S, Oki Y, et al. Factors associated with fluorine-18-fluorodeoxyglucose uptake in benign thyroid nodules. Endocr $J$ 2013;60:985-90. DOI PubMed

112. Olivier M, Eeles R, Hollstein M, Khan MA, Harris CC, Hainaut P. The IARC TP53 database: new online mutation analysis and recommendations to users. Hum Mutat 2002;19:607-14. DOI PubMed

113. Ghanem M, Levy Y, Mazeh H. Preoperative diagnosis of benign thyroid nodules with intermediate cytology. Gland Surg 2012;1:8991. DOI PubMed PMC

114. Alexander EK, Schorr M, Klopper J, et al. Multicenter clinical experience with the afirma gene expression classifier. $J$ Clin Endocrinol Metab 2014;99:119-25. DOI PubMed

115. Nikiforov YE, Carty SE, Chiosea SI, et al. Impact of the multi-gene ThyroSeq next-generation sequencing assay on cancer diagnosis in thyroid nodules with atypia of undetermined significance/follicular lesion of undetermined significance cytology. Thyroid 2015;25:1217-23. DOI PubMed PMC

116. Steward DL, Carty SE, Sippel RS, et al. Performance of a multigene genomic classifier in thyroid nodules with indeterminate cytology: a prospective blinded multicenter study. JAMA Oncol 2019;5:204-12. DOI PubMed PMC

117. Labourier E, Shifrin A, Busseniers AE, et al. Molecular testing for miRNA, mRNA, and DNA on fine-needle aspiration improves the preoperative diagnosis of thyroid nodules with indeterminate cytology. J Clin Endocrinol Metab 2015;100:2743-50. DOI PubMed PMC

118. Endo M, Sipos JA, Ringel MD, et al. Prevalence of cancer and the benign call rate of afirma gene classifier in ${ }^{18} \mathrm{~F}-$ Fluorodeoxyglucose positron emission tomography positive cytologically indeterminate thyroid nodules. Cancer Med 2021;10:108490. DOI PubMed PMC

119. Haugen BR, Alexander EK, Bible KC, et al. 2015 American thyroid association management guidelines for adult patients with thyroid nodules and differentiated thyroid cancer: the American thyroid association guidelines task force on thyroid nodules and differentiated thyroid cancer. Thyroid 2016;26:1-133. DOI PubMed PMC

120. NCCN Clinical practice guidelines in oncology: thyroid carcinoma 2020. Available from: https://www.nccn.org/professionals/physician_gls/pdf/thyroid.pdf [Last accessed on 3 Aug 2021].

121. Amin F, Byrd DR, Brookland PK, et al. AJCC cancer staging manual. 8th ed. New York: Springer International Publishing, 2017.

122. Ito Y, Miyauchi A, Oda H. Low-risk papillary microcarcinoma of the thyroid: a review of active surveillance trials. Eur J Surg Oncol 2018;44:307-15. DOI PubMed

123. Nguyen XV, Job J, Fiorillo LE, Sipos J. Thyroid incidentalomas: practice considerations for radiologists in the age of incidental findings. Radiol Clin North Am 2020;58:1019-31. DOI PubMed

124. Mazzaferri EL. Long-term outcome of patients with differentiated thyroid carcinoma: effect of therapy. Endocr Pract 2000;6:469-76. 
DOI PubMed

125. Grebe SK, Hay ID. Thyroid cancer nodal metastases: biologic significance and therapeutic considerations. Surg Oncol Clin N Am 1996;5:43-63. PubMed

126. Kim TY, Kim WG, Kim WB, Shong YK. Current status and future perspectives in differentiated thyroid cancer. Endocrinol Metab (Seoul) 2014;29:217-25. DOI PubMed PMC

127. Stack BC Jr, Ferris RL, Goldenberg D, et al; American Thyroid Association Surgical Affairs Committee. American Thyroid Association consensus review and statement regarding the anatomy, terminology, and rationale for lateral neck dissection in differentiated thyroid cancer. Thyroid 2012;22:501-8. DOI PubMed

128. Angell TE, Maurer R, Wang Z, et al. A cohort analysis of clinical and ultrasound variables predicting cancer risk in 20,001 consecutive thyroid nodules. J Clin Endocrinol Metab 2019;104:5665-72. DOI PubMed

129. Frates MC, Benson CB, Doubilet PM, et al. Prevalence and distribution of carcinoma in patients with solitary and multiple thyroid nodules on sonography. J Clin Endocrinol Metab 2006;91:3411-7. DOI PubMed

130. Sklar C, Whitton J, Mertens A, et al. Abnormalities of the thyroid in survivors of Hodgkin's disease: data from the Childhood Cancer Survivor Study. J Clin Endocrinol Metab 2000;85:3227-32. DOI PubMed

131. Schneider AB, Ron E, Lubin J, Stovall M, Gierlowski TC. Dose-response relationships for radiation-induced thyroid cancer and thyroid nodules: evidence for the prolonged effects of radiation on the thyroid. J Clin Endocrinol Metab 1993;77:362-9. DOI PubMed

132. Charkes ND. On the prevalence of familial nonmedullary thyroid cancer in multiply affected kindreds. Thyroid 2006;16:181-6. DOI PubMed

133. Nguyen XV, Roy Choudhury K, Tessler FN, Hoang JK. Effect of tumor size on risk of metastatic disease and survival for thyroid cancer: implications for biopsy guidelines. Thyroid 2018;28:295-300. DOI PubMed

134. Smith-Bindman R, Lebda P, Feldstein VA, et al. Risk of thyroid cancer based on thyroid ultrasound imaging characteristics: results of a population-based study. JAMA Intern Med 2013;173:1788-96. DOI PubMed PMC

135. Middleton WD, Teefey SA, Reading CC, et al. Multiinstitutional analysis of thyroid nodule risk stratification using the American college of radiology thyroid imaging reporting and data system. AJR Am J Roentgenol 2017;208:1331-41. DOI PubMed

136. Trimboli P, Paone G, Treglia G, et al. Fine-needle aspiration in all thyroid incidentalomas at ${ }^{18} \mathrm{~F}-\mathrm{FDG}$ PET/CT: Can EU-TIRADS revise the dogma? Clin Endocrinol (Oxf) 2018;89:642-8. DOI PubMed

137. Trimboli P, Knappe L, Treglia G, et al. FNA indication according to ACR-TIRADS, EU-TIRADS and K-TIRADS in thyroid incidentalomas at ${ }^{18} \mathrm{~F}$-FDG PET/CT. $J$ Endocrinol Invest 2020;43:1607-12. DOI PubMed 